\title{
Strike-induced chemical preferences in prairie rattlesnakes (Crotalus viridis)
}

\author{
TED MELCER and DAVID CHISZAR \\ University of Colorado, Boulder, Colorado
}

\begin{abstract}
Prairie rattlesnakes (Crotalus viridis) received exposure to a mouse carcass misted with diluted perfume during predatory strikes, just before or after striking, or in the absence of a strike. They then received a choice between a pair of nonenvenomated carcasses, one misted with the perfume and the other misted with a novel solution. Snakes that struck a perfume-misted carcass preferred the nonenvenomated carcass with chemical cues matching those on the carcass they had struck. However, exposure to chemical cues without striking produced no such preference even when the concentration of perfume solution was 100 times that used in the strike condition. Moreover, exposure to chemical cues just before or after the striking of an unscented carcass produced no subsequent preference for a carcass with matching cues. These results indicate the importance of the predatory strike rather than simple familiarization in the formation of chemical preferences in rattlesnakes.
\end{abstract}

Many species of rattlesnakes specialize on rodent prey (Klauber, 1956; Pough \& Groves, 1983). During typical predatory episodes, a snake makes very brief contact $(0.3 \mathrm{sec})$ with the prey during the strike and then immediately releases it (Kardong, 1986). The snake then locates and ingests the rodent's carcass by following the trail of chemical cues deposited as the rodent wanders away from the site of attack (Chiszar, Radcliffe, Scudder, \& Duvall, 1983; Golan, Radcliffe, Miller, O'Connell, \& Chiszar, 1982). Recently, we discovered a potentially important mechanism by which a rattlesnake could discriminate the chemical trail left by its prey from the array of chemical cues in the area (i.e., those left by other rodents that have foraged nearby). Snakes acquired a preference for specific chemical cues on their prey, which guided the subsequent search and ingestion (Melcer \& Chiszar, 1989). In that study, preferences were seen after snakes delivered a single predatory strike to rodents bearing distinct scents.

The nature of the experience necessary to induce this chemical preference remains to be analyzed. One hypothesis is that pairing chemical cues with a predatory strike is critical for inducing a later preference (i.e., associative learning is involved). Alternatively, mere exposure or familiarization with the chemical cues (Sluckin, 1964) might induce a subsequent preference (cf. Alberts, 1981; Galef \& Kaner, 1980; Halpern, 1987). Burghardt (1968, 1970) suggested that formation of a chemical preference depends on the act of striking. In his study, a subset of garter snakes struck at chemical cues (worm or fish ex-

An earlier version of this manuscript contained only Experiments 1 and 3. We thank V. LoLordo and an anonymous reviewer for insisting on the addition of Expriments 2 and 4, as these data enhance the message of the paper. We also thank Robert Barba for his assistance in data collection. Correspondence may be addressed to Ted Melcer at Department of Psychology, Murray State University, Murray, KY 42071. tract) on a cotton swab. Later, these snakes were more likely to strike at the same cues than were snakes that initially habituated to similar cues (i.e., eventually failed to strike). The subgroup of snakes that habituated preferred to strike at novel chemical cues.

In the present experiments, we investigated the acquisition of chemical preferences in rattlesnakes following mere exposure to chemical cues without the delivery of a predatory strike (Experiments 1 and 2), and following exposure to chemical cues prior to, during, and after striking prey (Experiments 3 and 4).

\section{EXPERIMENT 1}

In our previous experiments, rattlesnakes struck a mouse carcass misted with a perfume and then received a choice between two nonenvenomated carcasses. One was misted with the perfume experienced during the strike and the other was misted with a different scent. The rattlesnakes preferred the carcass with the chemical cues matching those on the carcass that had been struck (also, rattlesnakes acquire similar preferences for chemical cues arising from the rodent's diet; see Melcer \& Chiszar, 1989). In the present experiment, we tested the possibility that exposure to an odor in the absence of a predatory strike (mere exposure) might also induce a preference for prey with matching chemical cues.

\footnotetext{
Method

Subjects. Six adult prairie rattlesnakes (Crotalus viridis) about $70 \mathrm{~cm}$ long were subjects. The snakes were captured as adults and maintained individually in glass terraria $(50 \times 27.5 \times 30 \mathrm{~cm})$ containing paper floor coverings and stainless steel vessels filled with water. The room was kept at $26^{\circ}-28^{\circ} \mathrm{C}$ during photophase (0700-1900) and at $22^{\circ}-24^{\circ} \mathrm{C}$ during the scotophase. All the snakes had been in captivity for several years and had been accepting rodent prey (Mus musculus or preweanling Rattus norvegicus,
} 
20-27 g) on a biweekly schedule. Previously euthanized rodents were fed to snakes, and these carcasses were always suspended into the snakes' home cages from forceps in order to elicit predatory strikes. Consequently, the snakes were accustomed to striking prior to ingesting prey. The snakes had not eaten for 2 weeks prior to testing. Although the snakes had been used in previous experiments involving presentation of chemical stimuli, no surgical or pharmacological manipulations had been performed on them. Therefore, we consider these snakes typical of long-term captives.

Procedure. All snakes were observed in their home cages. First, a mouse carcass was misted with about $1 \mathrm{cc}$ of either diluted perfume (Jungle Gardenia, $2 \mathrm{cc} / 710 \mathrm{cc}$ tap water) or water. No live rodents were used; they were euthanized by cervical dislocation 2 min prior to the experiment. All the mice were culls from local breeding facilities, and all carcasses were eventually ingested by the snakes. The lid of the home cage was opened, and a perfume$(N=3)$ or water-misted carcass $(N=3)$ was suspended from forceps about $20 \mathrm{~cm}$ above and slightly in front of the snake's head for $6 \mathrm{sec}$. The snakes oriented themselves toward the carcass and emitted some tongue flicks (an important indicator of chemical recep tion; see Burghardt, 1970, 1980), but they were not permitted to approach close enough to strike. Our usual strike procedure is similar, except that the carcass is suspended $10 \mathrm{~cm}$ from the snake's head and the snake usually strikes within $3 \mathrm{sec}$ (Melcer \& Chiszar, in press). Following the 6 sec of exposure, the misted carcass was removed without making contact with any part of the home cage, and the cage lid was closed.

The misted carcass was discarded, and two additional carcasses were used for the prey-choice test, one misted with the diluted perfume and one misted with water. The carcasses were confined within wire mesh bags (each $13.5 \times 9.0 \mathrm{~cm}$ ). The bags were placed $5 \mathrm{~cm}$ apart and secured on a wooden base $(13.5 \times 23 \times 3.5 \mathrm{~cm})$, which was placed in the snake's home cage $5 \mathrm{~min}$ after initial exposure to the misted carcass. The bags containing the matching and nonmatching carcasses were equally often on the snakes' right or left. The prey-choice test lasted $10 \mathrm{~min}$. We recorded the amount of time the snake's head was facing and within $2.5 \mathrm{~cm}$ of each bag, and the number of tongue flicks emitted in each of these positions. These data were recorded during consecutive 2 -min intervals of the preychoice test. Interobserver agreement for these measures has been uniformly high in previous experiments (e.g., Chiszar, Radcliffe, O'Connell, \& Smith, 1981; Chiszar et al., 1983; Duvall, Scudder, \& Chiszar, 1980)

\section{Results and Discussion}

Exposure to chemical cues in the absence of a predatory strike failed to induce a preference for the carcass with matching cues. We found no evidence of preference for the matching over the nonmatching carcass during any 2 -min interval of the prey-choice test (all $p s>.05$ ). The mean amount of time spent investigating both carcasses during the 10-min test was $89.8 \mathrm{sec}(S E=43.2 \mathrm{sec})$, and the matching and nonmatching carcasses received equivalent investigation time $[t(5)=1.04, p>.05]$. Likewise, the mean number of tongue flicks directed at carcasses during the 10-min test was $64.3(S E=33.2)$, and the two types of carcasses each received about half of these tongue flicks $[t(5)=1.16, p>.05]$.

Two snakes did not investigate either carcass, two snakes had numerical values favoring the matching carcass, and two snakes had numerical values in the opposite direction. We conclude that mere exposure of prairie rattlesnakes to chemical cues in the absence of a predatory strike does not induce preferences for those cues (see
Chiszar, Stimac, \& Boyer, 1983; Radcliffe, Estep, Boyer, \& Chiszar, 1986 for related data showing that no-strike presentations of rodent prey produce generally low levels of chemosensory investigation in rattlesnakes).

\section{EXPERIMENT 2}

The results of Experiment 1 suggest that the predatory strike rather than simple familiarization with an odor produced the chemical-cue preferences reported by Melcer and Chiszar (1989). However, it remains possible that striking the scented carcass produced stronger chemical stimulation than the snakes experienced during no-strike presentations of similar carcasses in Experiment 1. Therefore, we repeated the procedure of Experiment 1 , increasing the concentration of the perfume solution by a factor of 100 . The rattlesnakes were exposed to a scented mouse carcass but were not permitted to strike it. Thus, the snakes should have experienced chemical stimulation from the carcass at least as strongly as they experienced it while striking carcasses scented with much more diluted perfume solutions (Melcer \& Chiszar, 1989; see also Experiments 3 and 4 below). If mere exposure to chemical cues is sufficient to induce a preference, rattlesnakes should prefer the carcass with familiar chemical cues during the prey-choice test.

\section{Method}

Subjects. Six prairie rattlesnakes from Experiment 1 were subjects. Housing and deprivation conditions were as described for Experiment 1 .

Procedure. The procedures of Experiment 2 were the same as those described for Experiment 1, apart from the following exceptions: We increased the concentration of perfume (Jungle Gardenia) solution by a factor of 100 (Experiment $1: 2 \mathrm{ml}$ perfume $/ 710 \mathrm{cc}$ water, or $0.28 \%$ perfume solution; Experiment 2: $28 \%$ perfume solution). Also, each snake was tested twice. On one trial, each snake was exposed to a mouse carcass misted with perfume solution, and on the other trial ( $24 \mathrm{~h}$ later), the snake was exposed to a carcass misted with water. The ordering of trials was counterbalanced across snakes. Each snake received a prey-choice test at the end of each trial: a simultaneous choice between two new carcasses, one misted with water and the other, with the $28 \%$ perfume solution. Each snake's responding to the matching/nonmatching carcasses was averaged across the two trials.

\section{Results and Discussion}

Rattlesnakes that received exposure to a strongly scented carcass in the absence of a predatory strike later failed to show any preference for a carcass with matching chemical cues. All snakes investigated the carcasses during the prey-choice tests. However, there were no significant differences between investigation (time or tongue flicks) of matching and nonmatching carcasses during any 2-min interval of the prey-choice test. The mean amount of time spent over the carcasses during the prey-choice test was $70.2 \mathrm{sec}(S E=17.8 \mathrm{sec})$, and the matching and nonmatching carcasses received equivalent investigation time $[t(5)=1.35, p>.05]$. The mean number of tongue flicks over the carcasses was $46.0(S E=14.7)$ and the snakes directed an equivalent number of flicks at the 
matching and nonmatching carcasses $[t(5)=1.00$, $p>.05]$.

The results of Experiment 2 are particularly important, because the snakes were exposed to a perfume solution that was much stronger than a solution that snakes prefer when it has been experienced during predatory strike. Yet the rattlesnakes did not form preferences for these chemical cues when experiencing them in the absence of the strike. Accordingly, Experiments 1 and 2 suggest that the strike-related preferences in rattlesnakes (Melcer \& Chiszar, 1989) are dependent on an association of chemical cues with the strike rather than on simple familiarization with the cues.

\section{EXPERIMENT 3}

If associative learning is involved in the formation of chemical preferences, rattlesnakes might also prefer chemical cues presented just prior to striking an untreated carcass. Furthermore, according to standard findings with classical conditioning procedures (Schwartz, 1978), snakes should show a lesser preference for chemical cues presented just after a predatory strike. Finally, we included a replicaton of our previous procedure (Melcer \& Chiszar, 1989), in which snakes experienced chemical cues simultaneous with the strike-that is, the cues were on the carcass that was struck.

\section{Method}

Subjects. Eight adult prairie rattlesnakes ( 5 from Experiment 1 and 3 other snakes) were subjects. The housing conditions and history of these snakes were as described for Experiment 1.

Procedure. All snakes were observed in their home cages. In the prestrike trials, a mouse carcass misted with diluted perfume (Jungle Gardenia or Tea Rose, $2 \mathrm{cc}$ perfume/710 cc tap water) was suspended into the snake's home cage outside of striking range for $6 \mathrm{sec}$ (as described for the no-strike procedure in Experiment 1). This carcass was removed, and $30 \mathrm{sec}$ later, an unscented carcass was presented so that the snakes could readily deliver a predatory strike. The struck carcass was removed, and 5 min later, the snakes received a choice between two nonenvenomated carcasses, each confined with a wire mesh bag. One carcass was misted with Jungle Gardenia and the other with Tea Rose. The use of two perfumes ensured that the snakes' preference during the prey-choice test would not be biased from experience with the untreated mouse during the strike.

For poststrike exposure, a perfume-misted carcass was presented outside of striking range about $30 \mathrm{sec}$ after the snake struck an unscented carcass.

All snakes received two trials (one trial per day), and the ordering of trials for each snake was random. Four snakes received exposure to a carcass misted with Jungle Gardenia during pre- and poststrike trials, and the other 4 snakes were exposed to Tea Rose during pre- and poststrike trials.

Two weeks later, all snakes were tested in a replication of our previous procedure (Melcer \& Chiszar, 1989), with Tea Rose and Jungle Gardenia perfumes. The snakes were permitted to strike a mouse misted with Tea Rose or Jungle Gardenia and were then given the prey-choice test described above. Each snake was tested, once after its having struck a carcass misted with Tea Rose and once after its having struck a carcass misted wtih Jungle Gardenia. The order of Tea Rose and Jungle Gardenia trials was counterbalanced across snakes.

\section{Results and Discussion}

The snakes exhibited low levels of investigation of the carcasses during the first 2 min of the prey-choice test, probably because of the amount of disturbance necessitated by our procedures. During pre- and poststrike exposure trials, the cages had to be opened twice in rapid succession, and the experimenter had to be moving quite a bit in order to introduce and withdraw the scented and unscented mice, as well as to introduce the test apparatus. O'Connell, Chiszar, and Smith (1981) showed that brief disturbances delay the onset of strike-induced chemosensory searching by several minutes, so we omitted minutes 1 and 2 of our test data and analyzed performance from minutes 3 through 10 for all conditions.

The snakes showed no significant differences in levels of investigation (time, tongue flicks) among the prestrike, poststrike, and strike exposure trials $(p s>.05)$.

Pre- and poststrike trials. Figure 1 (top) shows the results of the prey-choice test for trials in which the snakes were exposed to a perfume just prior to striking an unscented carcass. Investigation of matching and nonmatching carcasses was equivalent as indicated by the number
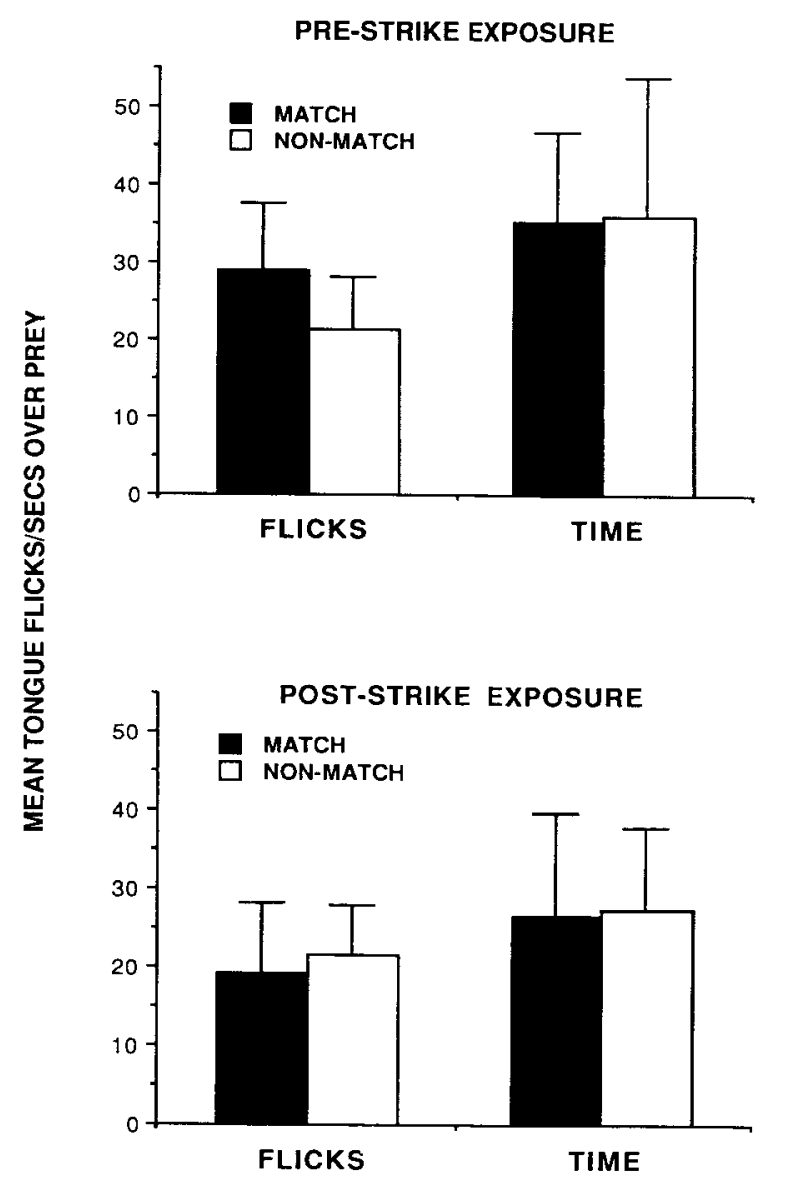

Figure 1. Mean ( $+S E$ ) investigation of matching and nonmatching carcasses during the prey-choice test following prestrike (top) or poststrike exposure to a scented mouse carcass. The number of tongue flicks (left) and number of seconds (right) over each carcass are shown in each graph. 

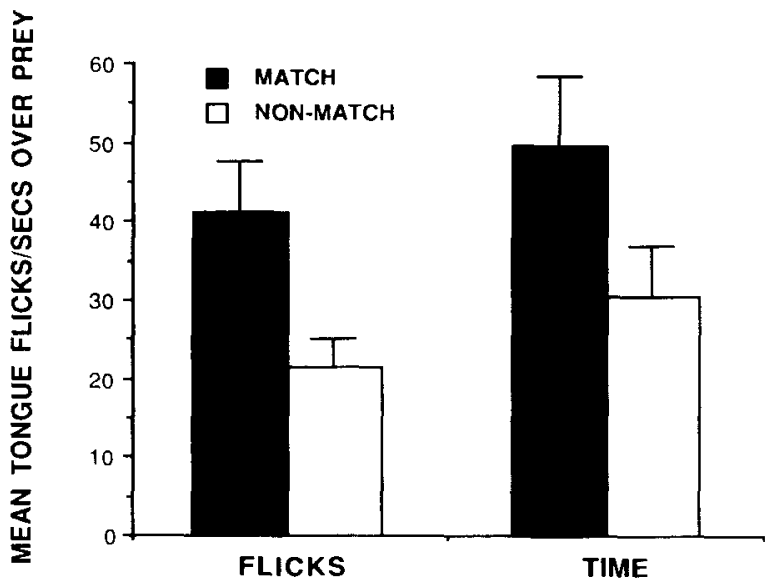

Figure 2. Mean ( $+S E$ ) investigation of matching and nonmatching carcasses during the prey-choice test after snakes struck a scented mouse carcass. The number of tongue flicks (left) and number of seconds (right) over each carcass are shown.

of tongue flicks (left) and amount of time spent (right) over the carcasses. Thus, our attempt to induce a chemical preference by exposing snakes to a perfume just before striking was unsuccessful.

Figure 1 (bottom) also shows investigation of matching and nonmatching carcasses on trials in which perfume exposure occurred just after striking. Again, there were no differences in investigation of matching and nonmatching carcasses for either measure (tongue flicking, left; time, right). Thus, neither exposure to chemical cues alone (Experiments 1 and 2), nor similar exposure in the general context of predatory strikes (just before or afterwards), produced any subsequent preference for a carcass with matching chemical cues.

Strike-exposure trials. Figure 2 shows data from preychoice tests after the snakes struck a carcass misted with a perfume. The snakes preferred the carcass with the same cues that had been applied to the mouse they had struck; they exhibited more tongue flicks at matching than nonmatching carcasses $[t(7)=2.92, p<.05]$ and spent more time over the matching than the nonmatching carcass $[t(7)=2.09, p<.05]$. These results are consistent with those reported by Melcer and Chiszar (1989).

\section{EXPERIMENT 4}

We attempted to replicate the strike-related preference in Experiment 3, using a perfume solution that was 100 times more dilute than the solution used to demonstrate this phenomenon (Melcer \& Chiszar, 1989; Experiment 3 above). Such a finding (in addition to the data of Experiment 2) would suggest that the chemical preference was dependent on pairing the odor with the strike rather than on the intensity of the rattlesnakes' exposure to the scented carcass.

\section{Method}

Subjects. Six rattlesnakes from Experiments 1 and 2 were subjects. Housing and deprivation conditions were as described previously.

Procedure. The procedure was the same as in Experiment 2, apart from the following exceptions: The snakes struck a carcass misted with water or diluted perfume (Jungle Gardenia, $.0028 \%$ solution) and later received the prey-choice test between nonenvenomated carcasses misted either with water or with the $.0028 \%$ perfume solution.

\section{Results and Discussion}

In the prey-choice test following the strike, the snakes investigated the matching carcass (time, $M=105.7 \mathrm{sec}$, $S E=20.2 \mathrm{sec}$; flicks, $M=87.0, S E=12.4$ ) more than the nonmatching one (time, $M=63.3 \mathrm{sec}, S E=$ $22.2 \mathrm{sec}$; flicks, $M=54.0, S E=13.6$ ), but these differences were not statistically significant $(.15>p s>.05)$. These data were transformed into percentages, and a significant preference for the matching over the nonmatching carcass was found [time, $t(5)=2.47, p<.05$; flicks, $t(5)=2.47, p<.05]$, suggesting that rattlesnakes formed at least weak chemical preferences during the strike, even when an extremely dilute solution was applied to the carcass struck. We also transformed the data from the no-strike trials of Experiments 1 and 2, but again, we found no significant differences between investigation of matching and nonmatching carcasses $(p s>.05)$.

\section{GENERAL DISCUSSION}

Rattlesnakes acquire a preference for specific chemical cues experienced during predatory strikes (Melcer \& Chiszar, 1989; Experiments 3 and 4, above). The present experiments suggest that experience with chemical cues must occur within the narrow temporal band of striking prey. Our various types of exposure to chemical cues outside of this temporal window failed to produce any later preference for prey with matching cues.

It is possible that exposure to the scented carcass during the strike produced stronger chemical stimulation than did exposure to a scented carcass held out of striking range. However, the no-strike presentations of chemical cues lasted twice as long as strike presentations, and (in Experiment 2) the concentration of perfume solution was 100 times as strong as the solution used in the strike trials of Melcer and Chiszar (1989). The snakes appeared to have detected the odor; in the no-strike experiments, they oriented themselves toward the carcass and emitted some tongue flicks. These no-strike exposure procedures simply did not produce an effect on the snakes' subsequent investigation of prey.

The present experiments suggest that the chemical preferences we have observed (Melcer \& Chiszar, 1989) depend on a simultaneous pairing of chemical cues on the prey with the predatory strike. The restrictive parameters of such a conditioning mechanism might enhance the rattlesnake's predatory efficiency, since the snakes need 
to follow the specific trail left by the struck prey. Acquisition of a preference for other chemical cues (i.e., from nearby plants or other potential prey that have recently passed by) might interfere with subsequent trailing of the specific cues left by the struck prey.

\section{REFERENCES}

AlberTs, J. R. (1981). Ontogeny of olfaction: Reciprocal roles of sensation and behavior in the development of perception. In R. N. Aslin, J. R. Alberts, \& M. R. Petersen (Eds.), Development of perception: Psychobiological perspectives (pp. 322-357). New York: Academic Press.

BurghardT, G. M. (1968). The reinforcement potential of the consummatory act in the modification of chemical-cue preferences. American Zoologist, 8, 745.

BurghardT, G. M. (1970). Chemical perception in reptiles. In J. S. Johnston, Jr., D. G. Moulton, \& A. Turk (Eds.), Communication by chemical signals. New York: Appleton-Century-Crofts.

BurghardT, G. M. (1980). Behavioral and stimulus correlates of vomeronasal functioning in reptiles: Feeding, grouping, sex and tongue use. In D. Muller-Schwarze \& R. Silverstein (Eds.), Chemical signals: Vertebrates and aquatic invertebrates (pp. 275-301). New York: Plenum.

Chiszar, D., Radcliffe, C. W., O'Connell, B., \& Smith, H. M. (1981). Strike-induced chemosensory searching in rattlesnakes (Crotalus viridis) as a function of disturbance prior to presentation of rodent prey. Psychological Record, 32, 57-62.

Chiszar, D., Radcliffe, C. W., Scudder, K. M., \& Duvall, D. (1983). Strike-induced chemosensory searching by rattlesnakes: The rolè of envenomation-related chemical cues in the post-strike environment. In D. Muller-Schwarze \& R. Silverstein (Eds.), Chemical signals in vertebrates 3 (pp. 1-24). New York: Plenum.

Chiszar, D., Stimac, K., \& Boyer, T. (1983). Effect of mouse odors on visually-induced and strike-induced chemosensory searching in prairie rattlesnakes (Crotalus viridis). Chemical Senses, 7, 301-308.

Chiszar, D., Stimac, K., Poole, T., Miller, T., Radcliffe, C. W., \& SMITH, H. M. (1983). Strike-induced chemosensory searching in cobras (Naja naja kaouthia, N. Mossambica pallida). Zeitschrift für Tierpsychologie, 63, 51-62.

Duvall, D., Scudder, K. M., \& Chiszar, D. (1980). Rattlesnake predatory behavior: Mediation of prey discrimination and release of swallowing by cues arising from envenomated mice. Animal Behaviour, 28, 674-683.

GALEF, B. G., JR., \& KANER, H. C. (1980). Establishment and maintenance of preference for natural and artificial olfactory stimuli in juvenile rats. Journal of Comparative \& Physiological Psychology, 94, 588-596.

Golan L., Radcliffe, C. W., Miller, T., O'Connell, B., \& Chiszar, D. (1982). Prey trailing by the prairie rattlesnake (Crotalus viridis). Journal of Herpetology, 16, 287-293.

HALPERN, M. (1987). The organization and function of the vomeronasal system. Annual Review of Neuroscience, 10, 325-362.

KARDONG, K. V. (1986). Predatory strike behavior of the rattlesnake, Crotalus viridis oreganus. Journal of Comparative Psychology, 100, 304-314.

KLAUBER, L. M. (1956). Rattlesnakes: Their habits, like histories and influence on mankind. Berkeley: University of California Press.

Melcer, T., \& Chiszar, D. (1989). Striking prey creates a specific chemical search image in rattlesnakes. Animal Behaviour, 37, 477-486.

O'Connell, B., Chiszar, D., \& SMITH, H. M. (1981). Effect of poststrike disturbance on strike-induced chemosensory searching in the prairie rattlesnake (Crotalus v. viridis). Behavioral \& Neural Biology, 32, 343-349.

Pough, F. H., Groves, J. E. (1983). Specializations of the body form and food habits of snakes. American Zoologist, 23, 443-454.

RadCliffe, C. W., Estep, K., Boyer, T., \& Chiszar, D. (1986). Stimulus control of predatory behavior in red spitting cobras (Naja mossambica pallida) and prairie rattlesnakes (Crotalus v. viridis). Animal Behaviour, 34, 804-814.

SCHWARTZ, B. (1978). Psychology of learning and behavior. New York: Norton.

SLUCKIN, W. (1964). Imprinting and early learning. Chicago: Aldine.

(Manuscript received July 20, 1988; revision accepted for publication October 20, 1988.) 